at the same time of converting atmospheric nitrogen into protein, which probably exist in soveral of the foregoing groups.

(7) Preliminary essays in this direction, the production of food yeast and of Chlorella have been discouraged by two factors: first, because insufficient attention has been directed to the preparation of sufficiently attractive materials from the crude micro-organism; socondly, and more important, by the demonstration that such products do not yet compete economically with orthodox foods. But, with increasing demands on orthodox food supplies, this situation may soon change.

(8) The world shortage seems likely to become acute in the next ten or twenty years, which is not a long period for developmental research of the nature likely to be requirod, especially as many of the relevant mieroorganisms have been little studied hitherto. 'To permit, application of such research in time, it is recommended that Governments encourage it now, even though it bo uneconomic at prosent.

\title{
THE CARNEGIE UNITED KINGDOM TRUST
}

T

HE forty-ninth annual report of the Carnegie United Kingdom Trust*, covering the year 1962, in which grant payments fell to $£ 74,870$ from $£ 152,533$ in 1961 , deals largely with the working out of settled policies in the second year of a quinquennium. A start was made with the distribution of a quinquennial allocation of $£ 100,000$ for the social requirements of new communities in offers of up to $£ 10,000$ to the Borough Council of Thetford, one-third of the possible cost of developing a central site for this purpose, and $£ 1,000$ to the Basildon Youth Association. A launching grant of $£ 3,000$ was made towards the establishment of the headquarters of a National Bureau for Co-operation in Child. Care. The quinquennial allocation of $£ 100,000$ for the youth service has now been committed to the extent of one-quarter in the form of improvement grants for 160 youth clubs, but there is still a dearth of new ideas which are pioneer in the national sense and not supported from other sources.

In the Arts, the Trust is maintaining its annual subvention of $£ 1,000$ to the Museums Association until the end of March 1964, and a special grant of $£ 1,000$ was awarded for up-to-date office equipmont and appointmonts in the Association's new headquarters. Sixteen expert reports were commissioned at the request of muscums throughout Britain, and arising out of these or earlier reports nine grants, totalling $\$ 5,350$, were recommended for immediate improvements in existing displays, and expenditure of $£ 6,000$ on museums reorganization included expenditure on schemes of improvement at twelve museums completed during the year and payments to account for expenditure on six similar projects.

Under education, besides the grants for youth service already noted, a small grant of $£ 270$ was made to the * The Carnegio United Kingdom Trust. 49th Annual Report, 1962
Pp. viii + 66. (Dunfermline, Fife: Carnegie United Kingdom Trust: 1963).
Young Men's Christian Association at Norwich to provido equipment for use in day camps for young people with which the Association is experimenting. The Trust is also contributing up to $£ 20,000$ towards the cost of a centre in the Brecon Beacons National Park, on a site adjacent to Mynydd Illtyd Common, as a mountain rendezvous and shelter on the understanding that the remaining capital cost and maintenance will bo provided by Government grant or local authorities. Bursaries were paid to 44 people attending courses at field-study centres in England and Wales and 24 to others attending courses in Scotland, and over the six years of this policy more than 500 people have received bursaries. Grants totalling $£ 915$ were made to archæological societies towards the cost of 14 prectical projects in which amateurs could be trained under skilled direction, and it is estimated that about 300 people participated, but only two applications were received for grants under a similar scheme for the benefit of natural history societies associated with the Council for Nature. A furthor grant of $£ 3,000$ went to the Couneil for Nature for the expenses of the Conservation Corps, which should become independent of the Trust's subvention by the end of 1963. Grant aid continued to the British Astronomical Association for promoting astronomy as a worth-while amateur activity, but only four events were carried through - three being wellattended open meetings, for which grants will not in future be available. Assistance is also being given to the Royal Meteorological Society to meet a growing interest in moteorology as an educational and cultural pursuit for amateurs and, for the four years 1962-65, £2,000 has been allocated at the rate of $\$ 500$ an year. In 1962 this was spont mainly on eight courses, five at field studies centres, one at Falmouth Sailing Centre on weather and sailing, and two on meteorology and gliding at Lasham Aerodrome, near Alton, and at Portmoak, Kinross-shire.

\section{TEXAS INSTRUMENTS INC.}

T HE 1962 annual report of Texas Instruments Inc. Dallas, Texas*, states that the Company continues to be the world's leading producer of semi-conduetors, although they constituted less than half tho Company's sales volume. Texas Instruments is one of few manufacturers the semi-conductor operations of which remained. profitable in the face of continued sovere price competition. It attributes this succoss to the emphasis placed on the mechanization of manufacturing processes. More than a hundred difforent types of transistors were introduced during 1962.

The report highlights the increasing demand for the Company's 'Solid Circuit' semi-conductor networks. 'These integrated circuit deviees are to bo used in the improved.

* Texas Instruments Inc. 1962 Annual Report. Pp. 8. (Dallas: Texas Instruments Inc., 1963.) version of the Minuteman intercontinental ballistic missilo, and initial production-quantity ordors totalling moro than a rnillion dollars havo been recoived. In addition, contracts for networks to be used in an improved airborne radar computer indicator for the naval $W 2 F-1$ oarlywarning aircraft and for use in an important airborne electronic countermeasures system have been obtainod. The production of new metallurgical, eloctrical and thermostatic devices reached a high lovel, as also nuclear core fabrication for which new contracts in excess of twenty-one million dollars were received during the year.

Dealing with goophysical activities, tho roport mentions that a numbor of significant new seismic signal enhancement methods which reached the production stage aided considerably the petroleum exploration services of the Company. The throe marine exploration vessels 
belonging to the Company were at work during most of the year in the Atlantic and Pacific Oceans, the Mediterranean Sea, and the Persian Gulf. The magnetic detection of nuclear weapon effects, the simulation of lunar environments, the analysis of radar terrain, and oceanographic systems and services were other fields of investigation undertaken by the Company.

To satisfy the growing need for its products, Texas Instruments has embarked on an extensive building pro- gramme. A building for plating operations on the Central Expressway site and the doubling to 60,000 sq. ft. of the main plant of the Company's subsidiary, Engineering Supply Co., have been completed, and in November 1962 the construction began of a 60,000 sq. ft. components plant near Nice, France, similar to the plants in Dallas and England. This was followed, in December, by the start of a 290,000 sq. ft. multi-purpose manufacturing plant on the Central Expressway site.

\title{
RADIATION QUANTITIES AND UNITS
}

\begin{abstract}
HE reports of the International Commission on Radiological Units and Measurements have been published in past years by the National Bureau of Standards in the Handbook series, and each of the triennial reports has constituted a complete restatement of the recommendations of the Commission. During 1962 , however, the Commission decided to modify its previous practice and Report $10 a *$ is the first of a new series of reports, each of which deals with one aspect only of the work of the Commission.

Report $10 a$ deals with radiation quantities and units and presents the recommendations of the Commission agreed at its meeting held in Montreux, during April $2-14,1962$. Report $10 b$ will deal with physical aspects of irradiation, Report $10 \mathrm{c}$ with radioactivity, Report $10 d$ with clinical dosimetry, Report $10 e$ with radiobiological

* United States Department of Commerce: National Bureau of Standards. Handbook No. 84: Radiation Quantities and Units-International Com

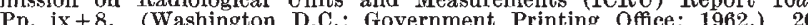
cents.
\end{abstract}

dosimetry, and Report $10 f$ with methods of evaluating radiological equipment.

The Commission recommends that the use of each special unit be restricted to one quantity, namely the radsolely for absorbed dose; the roentgen-for exposure; and the curie-for activity. Several new names are proposed. For protection purposes, the 'dose equivalent' $(D E)$ is introduced, defined as the product of absorbed dose, $D$, quality factor $(Q F)$, dose distribution factor $(D F)$ and other necessary modifying factors, and the unit of dose quivalent is the 'rem', being numerically equal to the dose in rads multiplied by the appropriate modifying factors. Another new name, "kerma", based on the initials of kinetic energy released in material, is for the quantity which represents the kinetic energy transferred to charged particles by the uncharged particles per unit mass of the irradiated medium. Others are 'energy fluence' with its related quantity 'particle fluence', and 'specific gamma ray constant'. The term 'activity' is recommended to be used for the transformation rate and its unit, the curie, defined as $3.7 \times 10^{10} \mathrm{sec}^{-1}$.

\section{THE UNSOLVED PROBLEM OF BALL LIGHTNING}

\section{BY STANLEY SINGER}

\author{
Rocket Power Inc., Research Laboratories, Pasadena, California
}

$\mathrm{T}$ HE International Conference on Atmospheric and Space Electricity, held on May 6-10 in Montreux, dealt with present problems of meteorological electrical phenomena. Scientists from twenty-five countries participated in discussions organized about major problem areas. Several of the most difficult questions were also those of the longest standing.

Storms in Nature exhibit marked electrical activity, the most readily observed result being ordinary lightning. One of the most controversial questions concerns the separation of charge in these storms. The processes which build up the electrical potentials and current involved in lightning have not been established. Laboratory investigations have provided information on charge separation occurring, for example, between the solid and liquid phases in the freezing of water ${ }^{1}$. The complexity and scale of natural storms have called forth more complex theories for which similar direct experimental data is lacking ${ }^{2}$. The problem of ball lightning has received much attention, including numerous experimental investigations; yet the available information is even more limited. The experiments have failed to duplicate major properties of the natural phenomenon, and it can only be said that promising explanations have been proposed.

Atmospheric potentials are responsible for several lightemitting phenomena, for example, the glowing spheres known as St. Elmo's fire. Although traditionally seen on the masts of sailing ships, these are also observed on trees, stones, and even human beings on mountain tops. St. Elmo's fire is usually attributed to the corona discharge caused by a potential at the tip of a protruding object such as a stake in the ground. The properties of this discharge account for the stable position of St. Elmo's fire. Ball lightning, on the contrary, can move over an extended path, according to many reports.

This extensive motion and other unusual properties have attracted notice to ball lightning although it is seen rarely compared with ordinary lightning. The great variety of phenomena reported during thunderstorms (including pinched lightning ${ }^{3}$, bead lightning, and St. Elmo's fire) and the nature of the reports have led to a not unreasonable suspicion of many observations of ball lightning. Witnesses are present by chance, usually in unsettling circumstances. Several accounts resemble folk-lore. It is not surprising, therefore, that some authorities, notably Humphreys ${ }^{4}$ and Schonland ${ }^{5}$, have expressed scepticism that ball lightning occurs. Humphreys examined 280 reported observations, and concluded that all but few were optical illusions resulting from an intense light such as ordinary lightning. The remaining few (less than half a dozen) he conceded might be examples of St. Elmo's fire. Several scientists, however, have reported viewing ball lightning; and photographs have been obtained ${ }^{6-8}$. None of the pictures is equal in quality to those available of the ordinary strokes of lightning, but two general aspects of the ball are recorded. One shows a stationary bright object not particularly spherical in shape, sometimes with glowing tentacles. The other records an illuminated path with well-defined boundaries apparently caused by motion of the ball. In view of continuing evidently authentic reports it appears that the best conclusion is that ball lightning does indeed exist. 